\title{
PENGALAMAN IBU DALAM MENDAPATKAN DUKUNGAN KELUARGA TERKAIT ANTENATAL CARE K4 DI PUSKESMAS SIDOREJO LOR SALATIGA
}

\author{
Arwyn W. Nusawakan', Treesia Sujana ${ }^{2}$, Elsa D. Simatupang ${ }^{3}$ \\ 1,2,3 Universitas Kristen Satya Wacana Salatiga \\ Email : arwyn.weynand@uksw.edu
}

\begin{abstract}
Abstrak
Antenatal Care atau kunjungan antenatal adalah pemeriksaan kesehatan ibu hamil selama masa kehamilan untuk mencegah terjadinya komplikasi yang dapat membahayakan ibu dan janin. Kualitas Pelayanan antanetal care terhadap ibu hamil perlu perhatian kusus sehingga dapat memenuhi standar pelayanan demi tercapainya tujuan kesehatan sesuai dengan target renstra kemenkes tahun 2017. Kunjungan antenatal oleh ibu hamil dipengaruhi oleh beberapa faktor salah satunya faktor keluarga. Dukungan keluarga menjadi salah satu dampak yang dapat mempengaruhi frekuansi dalam pemeriksaan antenatal care. adalah untuk mengetahui pengalaman ibu dalam mendapatkan dukungan keluarga terkait Antenatal care K4 di Puskesmas Sidorejo Lor Kota Salatiga. penelitian ini menggunakan jenis penelitian kualitatif dengan metode deskriptif. Teknik pengumpulan data yang digunakan oleh peneliti adalah wawancara mendalam (Deep Interview). sampel ibu dengan anak usia 0-1 tahun pada masa kehamilan tidak mencapai $\mathrm{K} 4$ pemeriksaan antenatal care. Pengetahuan ibu, dukungan keluarga dan ekonomi keluarga sangat mempengaruhi ibu dalam melakukan pemeriksaan antenatal care K4. Dukungan keluarga menjadi salah satu masalah, yang dapat mempengaruhi ibu untuk melakukan pemeriksaan antenatal care. Perhatian suami sangat penting untuk memotivasi ibu dalam menjaga kesehatan, serta melakukan pemeriksaan kandungan, dan perhatian suami juga dapat membuat ibu bahagia. Ekonomi keluarga yang rendah juga menjadi salah satu penyebab ibu tidak rutin melakukan pemeriksaan antenatal care. Keadaan sosial ekonomi sangat mempengaruhi kehamilan ibu karena berhubungan dengan pemenuhan kebutuhan-kebutuhan ibu selama kehamilan, kurangnya pengetahuan ibu dan keluarga mengenai pentingnya antenatal care, serta dukungan keluarga dari segi ekonomi dalam mendukukung kesehatan ibu dan janin, mengakibatkan ibu hamil tidak melakukan pemeriksaan antenatal care secara rutin.
\end{abstract}

Kata Kunci: Antenatal care; dukungan keluarga.

\begin{abstract}
Antenatal care or antenatal visits are health checks of pregnant women during pregnancy to prevent complications that can harm the mother and fetus. The quality of antenatal care services for pregnant women needs special attention that way; they can meet service standards to achieve health goals following the 2017 Ministry of Health strategic plan targets. Antenatal visits by pregnant women are affected by several factors, one of which is family factors. Family support is one of the impacts that can affect the frequency of antenatal care checks. The purpose of the study was to determine the experience of mothers in getting family support related to K4 Antenatal care at the Sidorejo Lor Health Center, Salatiga City. Research Methods this research uses qualitative research with descriptive methods. The data collection technique used by the researcher is the in-depth interview (Deep Interview). Sample Mothers with children aged 0-1 years during pregnancy did not reach $K 4$ for antenatal care examinations. Research Results Mother's knowledge, family support, and the family economy will affect mothers conducting antenatal
\end{abstract}


care K4 examinations. Family support is one of the problems, which can influence mothers to carry out antenatal care checks. The husband's attention is very important to motivate the mothers in maintaining health, as well as conducting an obstetrical examination, and the husband's attention can also make them happy.The low family economy is also one of the reasons why mothers do not routinely carry out antenatal care checks. Socio-economic conditions will affect the mother's pregnancy because it is related to meeting the needs of the mother during pregnancy, the lack of knowledge of mothers and families about the importance of antenatal care, as well as family support from an economic perspective in supporting maternal and fetal health, resulting in pregnant women not doing antenatal care checks routinely.

Keywords: Antenatal care; family support.

\section{PENDAHULUAN}

Upaya menurunkan angka kematian ibu di Indonesia masih menjadi salah satu prioritas capaian status kesehatan masyarakat di Indonesia. Salah satu yang penting dari berbagai upaya dan program serta kebijakan tersebut terkait dengan pemeriksaan Antenatal Care oleh ibu hamil. Antenatal Care adalah pemeriksaan kesehatan ibu hamil selama masa kehamilan untuk mencegah terjadinya komplikasi yang dapat membahayakan ibu dan janin.

Berdasarkan standar yang ditetapkan oleh Pemerintah Kesehatan Republik Indonesia, Ibu hamil didorong agar melakukan pemeriksaan antenatal secara rutin minimal 4 kali selama masa kehamilan. Empat kali pemeriksaan Antenatal Care terbagi dalam beberapa tahapan yaitu sekali pada trimester satu usia kehamilan 0 sampai 12 minggu, sekali pada trimester kedua usia kehamilan 12 sampai 24 minggu, dua kali pada trimester ketiga usia kehamilan 24 sampai 36 minggu. Penetapan standar minimal pemeriksaan Antenatal Care ini dilakukan agar ibu dan janin terpantau kondisi kesehatannya dan meminimalisir resiko-resiko masalah kehamilan seperti deteksi sedini mumgkin resiko kehamilan dan pencegahan atau penanganan komplikasi selama kehamilan (Kemenkes., 2016)

Pelayanan Antenatal Care terhadap ibu hamil diupayakan agar dapat memenuhi standar kualitas dalam pemeriksaan. Kementerian Kesehatan telah merumuskan pelayanan pada ibu hamil, pemeriksaan ibu hamil mencakup pengukuran berat badan dan tinggi badan, tekanan darah, status gizi lingkar lengan atas (LILA), tinggi fundus uteri, imunisasi tetanus (TT), konsumsi tablet zat besi, asesment persentase, menghitung denyut jantung janin dan pelayanan tes laboratorium (Hemoglobin dan golongan darah). Selain itu juga dilakukan tatalaksana kasus dan konseling serta perencanaan Keluarga Berencana. Hal lain terkait standar yang ditetapkan "Pedoman Pelayanan Antenatal" yaitu standar minimal pemeriksaan Antenatal Care yakni sebanyak 4 kali. Angka kunjungannya tersebut dinilai berdasarkan cakupan K1 (kunjungan Antenatal Care pertama) dan cakupan K4 (kunjungan Antenatal Care keempat). (Kemenkes., 2016)

Cakupan pelayanan kesehatan ibu hamil di Indonesia pada tahun 2017 K4 sebesar 87,3 persen data tersebut sudah memenuhi target Rencana Strategis Renstra tahun 2017 yaitu sebesar 76 persen (Kemenkes., 2017). Selain itu berdasarkan data Profil Kesehatan Provinsi Jawa Tengah tahun 2017, cakupan pelayanan Antenatal Care K1 dan K4 pada tahun 2017 adalah pemeriksaan K1 98,94 persen dan K4 92,53 persen dan data di Kota Salatiga pada tahun 2017 adalah K1 100 persen sendangkan K4 92,2 persen. (Dinas Kesehatan Provinsi Jawa Tengah, 2018).

Dari data K1 dan K4 terdapat selisi angka 7,8 persen yang berarti terdapat 
ibu hamil yang tidak melakukan kunjungan antenatal care secara penuh.

Kunjungan Antenatal Care oleh ibu hamil dipengaruhi oleh beberapa faktor. Menurut Lawrance Green dalam (Notoadmojo, 2010), faktor-faktor yang mempengaruhi perilaku kesehatan ibu hamil dalam melakukan kunjungan antenatal terbagi menjadi faktor predisposisi, faktor pemungkin dan faktor penguat. Faktor predisposisi adalah faktor yang mempengaruhi terjadinya perubahan perilaku seseorang, faktor predisposisi ibu hamil dalam melakukan kunjungan antenatal terdiri dari faktor usia, tingkat pendidikan, pekerjaan, paritas, pengetahuan dan sikap ibu hamil. Faktor pemungkin adalah faktor yang memfasilitasi perilaku atau tindakan, faktor pemungkin ibu hamil dalam melakukan kunjungan antenatal terdiri dari faktor jarak tempat tinggal dengan fasilitas kesehatan, penghasilan keluarga, serta sarana media informasi yang ada. Faktor penguat adalah faktor yang mendorong atau memperkuat terjadinya perilaku kesehatan, yang termasuk faktor penguat dalam mempengaruhi perilaku ibu hamil dalam melakukan kunjungan antenatal adalah dukungan suami, dukungan keluarga dan sikap serta dukungan dari petugas kesehatan. Hasil penelitian yang dilakukan oleh (Susanto et al., n.d.) bahwa ada hubungan dukungan keluarga dengan pemeriksaan antenatal care, tetapi tidak ada hubungan dengan dukungan petugas kesehatan dan kepercayaan dengan pemeriksaan antenatal care. Penelitian yang sama juga dilakukan oleh (Ritonggo, 2012) dalam penelitian nya mengatakan bahwa faktor-faktor yang mempengaruhi kunjungan pemeriksaan adalah faktor pengetahuan, pendidikan, umur, ekonomi, informasi, letak geografi dan dukungan keluarga.

Dari beberapa faktor diatas dukungan keluarga menjadi salah satu faktor yang dapat mempengaruhi Ibu hamil tidak melakuakan pemeriksaan antenatal care. Dukungan sosial yang paling dibutuhkan bagi ibu hamil dalam menghadapi priode antenatal care adalah keluarga (Indriyani., 2013).

Selama masa kehamilan sekitar 9 bulan ibu hamil mengalami masa-masa pertumbuhan janin yang membutuhkan dorongan mental dari lingkunganya (Anshor dan Abudllah, 2010) Dalam hal ini fungsi keluarga bagi ibu hamil sangat dibutuhkan agar ibu hamil bisa merasa senang, rasa aman, rasa puas dan rasa nyaman yang akan membuat ibu hamil merasa mendapat dukungan secara emosional yang akan mempengaruhi kesehatan jiwanya (Siti dan Mahmudah, 2010). Pada masa kehamilan, peran suami sangat penting untuk memotivasi istri terus menjaga kesehatan dengan memberi makanan yang bergizi, istirahat yang cukup, serta mendampingi ibu hamil setiap memeriksakan kehamilan (Anshor dan Abudllah, 2010).

Penelitian yang dilakukan oleh juga mengatakan bahwa jika seluruh keluarga mengharapkan kehamilan, mendukung bahkan memperlihatkan dukungannya dalam berbagai hal, maka ibu hamil akan merasa lebih percaya diri, lebih bahagia dan siap menjalani kehamilan sampai persalinan dan masa nifas. (Siti dan Mahmudah, 2010)

Dari latarbelakang tersebut peneliti tertarik untuk melakukan penelitian mengenai kesenjagan data antara pemeriksaan antanetal care $\mathrm{k} 1$ dengan $\mathrm{k} 4$ yang mana terdapat selisi 7,8 persen tidak melalukukan pemeriksaan $\mathrm{k} 4$. Dalam penelitian ini peneliti lebih tertarik melakukan penelitian dengan pendekatan penelitian kualitatif karena peneliti ingin terlibat secara langsung sebagai instrument penelitian demi mementingkan kealamiahan data secara faktual di lapangan oleh karena itu yang menjadi masalah dalam penelitian ini ialah bagaimana pengalaman ibu hamil dalam mendapatkan dukungan keluarga terkait pemerikasaan antenatal carae secara lengkap yakni pemeriksaan k1 sampai pemeriksaan k4 di Kota Salatiga.

Penelitian ini dilakukan dengan persetujuan etik universitas Kristen 
Satya Wacana, dengan nomor ethical clereance 210/PE/KEPK.UKSW/2019

\section{METODE}

Penelitian ini mengunakan metode kualitatif deskriptif. peneliti akan menggali pengalaman ibu ketika masa kehamilan terakhir. Terkait dengan hal tersebut, partisipan dalam penelitian ini dipilih berdasarkan Teknik purposive sampling dengan kriteria: ibu dengan anak usia 0-1 tahun, pada masa kehamilan tidak menjacapai K4 pemeriksaan Antenatal Care, berada dalam area binaan Puskesmas Sidorejo Lor Kota Salatiga. Penelitian ini telah dilakukan pada bulan Juli-Agustus 2019 di area binaan puskesmas Siodorejo Lor Kota Salatiga. Dalam penelitian ini menggunakan teknik pengumpulan data yakni wawancara mendalam (deep interview), peneliti menyusun

\section{HASIL DAN PEMBAHASAN}

Dalam penelitian ini terdapat 5 partisipan yang berada dalam binaan Puskesmas Sidorejo Lor Kota Salatiga yang tidak memenuhi pemeriksaan K4 dengan melihat buku Kesehatan Ibu dan Anak (KIA) partisipan. pertanyaan semi-terstruktur. Jumlah pertanyaan dalam penelitian ini adalah 10 pertanyaan wawancara yang setiap pertanyaannya rata-rata berkembang sampai 7 pertanyaan sesuai dengan kebutuhan data yang peneliti butuhkan. Data penelitian dianalisis menggunakan analisis tematik yaitu data telah direduksi, kemudian peneliti mengidentifikasi kata-kata kunci sebelum mengelompokannya menjadi kategorisasi data dan tema penelitian. Semua partisipan mendapatkan penjelasan terlebih dahulu tentang tujuan dan gambaran penelitian ini sebelum diminta menandatangani inform consent. Untuk menguji keabsaan data yang didapat peneliti telah bertanya kepada keluarga partisipan yang terdiri dari suami dan orang tua partisipan yang tinggal serumah dengan partisipan. (Sugiyono, 2016).

Berdasarkan hasil wawancara dan analisis data yang dilakukan dalam penelitian ini ditemukan satu tema berdasarkan pengalaman ibu dalam mendapatkan dukungan keluarga terkait pemeriksaan kehamilan K4 di Puskesmas Sidorejo Lor Kota Salatiga. Yakni sebagai berikut:

Kepatuhan ibu terkait antenatal care $\mathrm{K} 4$ di pengaruhi oleh beberapa faktor yaitu pengetahuan ibu, dukungan keluarga dan ekonomi.

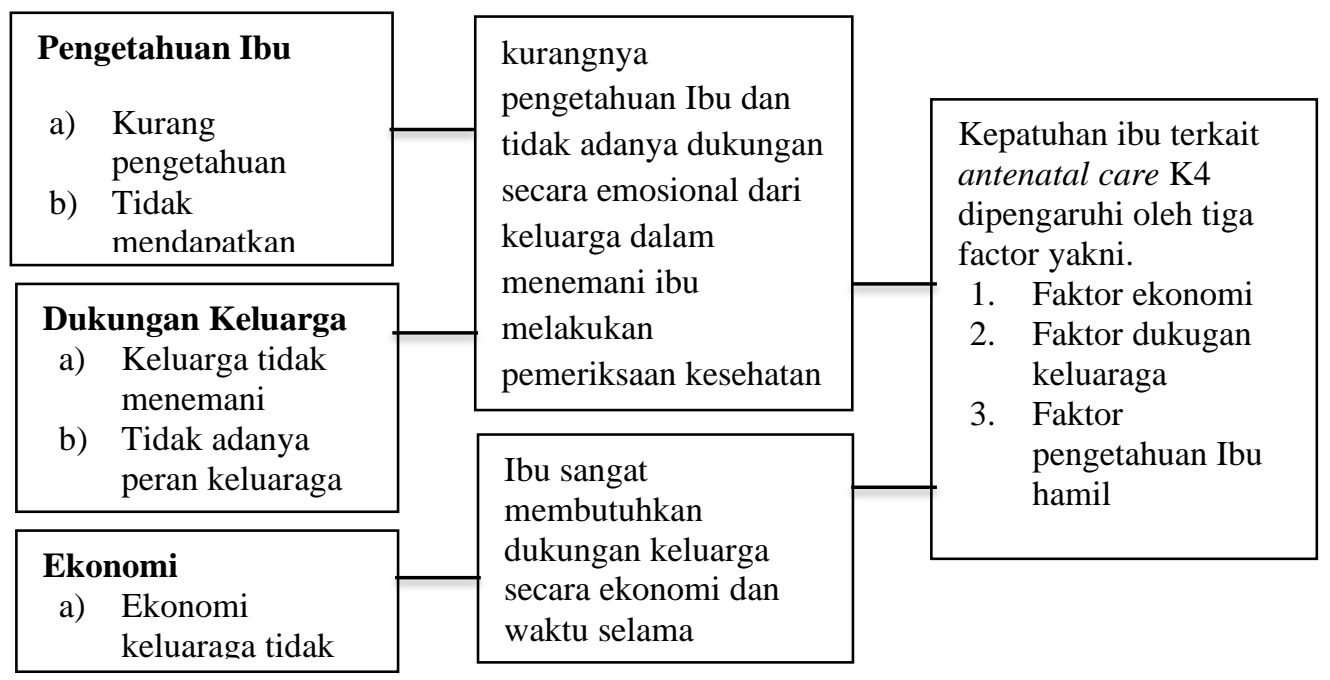


Kepatuhan ibu terkait ANC K4 dipengaruhi oleh tiga faktor yakni ekonomi, dukungan keluarga dan pengetahuan Ibu hamil.

Berdasarkan penelitian yang dilakukan mengungkapkan dukungan ekonomi, dukungan keluarga serta pengetahuan Ibu hamil, sangat mempengaruhi ibu dalam melakukan pemeriksaan antenatal care $\mathrm{K} 4$.

a) Pengetahuan Ibu

Pengetahuan Ibu tentang antenatal care sangat membantu Ibu dalam melakukan kunjungan antenatal care selama Ibu hamil. Kurangnya pengetahuan ibu tentang antenatal care berdampak pada ibu tidak melakukan pemeriksaan antenatal care secara rutin. Berdasarkan hasil wawancara peneliti menemukan bahwa pengetahuan ibu dapat membantu ibu dalam melakukan pemeriksaan antenatal care, menurut partisipan pemeriksaan kehamilan itu penting untuk mengetahui kesehatan ibu dan janin dalam perut, tetapi ibu merasa pemeriksaan secara rutin hanya untuk ibu yang mempunyai masalah selama kehamilan. Berikut pernyataan partisipan:

"Penting ibu. Pemeriksaan kandungan dilakukan untuk tahu kesehatan janin dalam perut, sama juga untuk tahu apa ibu nya sehat, supaya janin nya nanti tidak bermasalah di dalam perut sampe bayinya lahir nanti ibu. Kalau kata bidan sama saya minimal 4 kali periksa kehamilan. Seingat saya sudah 4 kali periksa. Tetapi saya tidak ingat lagi pas periksa itu umur kandungan saya berapa memang di buku KIA itu terakhir periksa umur kandungan 29 minggu saya pun tidak periksa lagi, lagian saya sehat-sehat saja, jadi buat apa saya periksa hasilnya sama saja setiap kali saya periksa" (P5)

pemeriksaan kehamilan itu penting karena kita dapat mengetahui kesehatan kandungan dari hasil pemeriksaan sehingga dapat membantu mencegah masalah pada saat melahirkan nanti. Kalau soal harus berapa kali periksa saya juga kurang tahu karna saya periksanya setiap bulan tetapi di buku
KIA saya haya sampai 26 minggu itu karena bayi saya lahirnya premature. (P2)

Dari pernyataan partisipan sesungguhnya memahami akan pentinnya pemeriksaan antenatal care, tetapi partisipan memahami hanya sebatas kepentingan kesehatan bayi saja sedangkan kesehatan ibu sendiri seakan terabaikan bahkan partisipan juga seakan tidak mengetahui sesungguhnya berapa kali harus melakukan pemeriksaan antenatal care selama kehamilan, partisipan pun tidak mengetahui kondisi dan letak bayi dalam persiapan melahirkan. Pengetahuan pemeriksan antenatal care sengat penting untuk kesehatan bayi dan ibu dalam persiapan persalinan, hal inilah yang perlu menjadi perhatian khusus agar setiap ibu yang sedang mengandung dapat betul memahami pentingnya pemeriksaan antenatal care sehingga dapat melakukan pemeriksaan secara rutin sampai pada fase melahirkan sehingga dapat mengurangi angka kematian ibu dan anak.

Hasil penelitian ini sejalan dengen penelitian yang dilakukan oleh (Windiyati \& Pebrian, 2017) yang mengatakan bahwa ada hubungan antara pengetahuan tentang resiko tinggi kehamilan dengan sikap dalam pemeriksaan antenatal care di Puskesmas Sungai Raya dalam tahun 2017. Selain itu hasil ini juga sesuai dengan penelitian yang dilakukan oleh (Febyanti N.K dan Susilawati, 2012) dengan hasil yang di dapat bahwa ada hubungan yang signifikat antar pengetahuan ibu hamil dengan perilaku kunjungan antenatal care.

b) Dukugan Keluarga

Dukungan keluarga juga berpengaruh bagi ibu agar dapat melakukan pemeriksaan antenatal care, terutama peranan suami, serta semua keluarga yang tinggal serumah dangan ibu hamil sangat di butuhkan dalam mendukung ibu hamil untuk melakukan pemeriksaan antenatal care. Dari data wawancara peneliti mendapati bahwa 
Ibu hamil memerlukan dukungan keluarga dalam menemani ibu melakukan pemeriksaan kandungan, ibu menjadi tidak termotivasi melakukan pemeriksaan kesehatan kandungan karena tidak adanya peran keluarga dalam mengingatkan dan menemani ibu melakukan pemeriksaan antenatal care. Berikut pernyataan partisipan:

"Waktu hamil ibu baik-baik saja, hanya seperti biasa yang orang-orang lain alami, ibu hanya rasa pusing dan kadang mual badan ibu juga kadang sakit terutama bagian belakang mungkin faktor umur juga. Suami jarang dirumah, jadi ibu kurang diperhatikan, ibu di sini tinggal sama ibu mertua dan paman suamiku, mertua juga sudah tua, jadi ibu juga kurang di perhatikan dari suami dan keluarga yang ada di rumah, itu yang buat ibu tidak pernah periksa karna tidak ada yang ingatin dan temani periksa, yang sering tanya itu bapaknya ibu, sering tanya kesehatan ibu, kalo lagi pas sakit ibu di suruh istirhat." (P1)

"Selama hamil saya tidak pernah sakit, kalo mual dan muntah kan wajar yah, itu saja yang saya rasa. Kalau keluarga mereka tidak melakukan apaapa, hanya lihat saja pada saat saya muntah, setelah itu di ambili air hangat terus saya hanya di suruh istirahat. lagian ini kehamilan saya yang kedua dan jarak dari anak pertama dan kedua cuman 2 tahun dan belajar dari kehamilan pertama ini cuman bawaan dari bayi saja". (P3)

Pernyataan partisipan tersebut menuturkan kurangnya dukungan keluarga dalam mendukung pemeriksaan kehamilan dikarenakan semua keluarga sangat sibuk dalam pekerjaannya masing-masing sehingga ibu juga seakan melupakan akan pemeriksaan kesehatan kehamilan. kondisi ibu yang merasa pusing, mual, dan muntah-muntuhpun sudah tidak menjadi perhatian bahkan hal tersebut sudah seakan menjadi biasa dalam pemahaman tentang ibu hamil sehingga tidak perlu pemeriksaan karena sudah diangap biasa bagi orang yang sementara mengandung. Kondisi tersebut seakan sudah biasa ketika mengandung.

Kurangnya perhatian suami dalam menayakan kondisi ibu dan bayi juga membuat ibu tidak memperhatikan kesehatan sehingga tidak melakukan pemeriksaan kesehatan kandungan.

Hasil penelitian ini sama dengan (Setanelly Dan Lestari, 2019) dengan judul penelitian faktor-faktor yang berhubungan dengan kunjungan antenatal care hasil penelitian mengatakan bahwa terdapat hubungan antara dukungan keluarga dengan kunjungan antenatal care.

\section{c) Ekonomi}

Ekonomi keluarga yang rendah juga menjadi salah satu penyebab ibu tidak rutin melakukan pemeriksaan antenatal care. Dari hasil wawancara yang peneliti lakukan ekonomi keluarga yang rendah membuat ibu harus ikut berkerja membantu keuangan keluarga, ibu menjadi tidak punya waktu untuk melakukan pemeriksaan antenatal care ke Puskesmas atau Bidan. Berikut pernyataan partisipan.

"suami nemani saya, kalo antriannya panjang suami pulang kan musti jualan, harus nyiapin jualan nya, jadi nanti saya tunggu di tempatnya dokter, kalo sudah selesai periksa nanti saya telpon suami kalo bisa jemput saya tunggu suami kalo tidak saya pulang pake ojek. Tidak pernah, dokternya kan selalu sore, jadi memang tidak pernah menemanii ketemu dokter, paling antar saja habis itu temani sebentar kalo sudah jamnya ayah mau jualan yah saya di tinggal gitu. Hidup saya susah, memang ada kendala sama biaya, cuman saya kan tidak mau ngerepoti suami dan anak, jadi saya simpansimpan uang, biasa kalo suami pulang jualan kan saya di kasih uang belanja misalnya kalo rame saya di kasih 50 ribu, 20 nya saya simpan 30 nya saya pake belanja sayur yah sedikit-sedikit, setidaknya bisa meringankan biaya dokter dan membantu nanti pas persalinan, sampe saya ngomong sama 
si kecil di perut jangan sakit-sakit yah dek, ibu hidupnya susah, terus saya bilang lahirannya harus normal yah dek, ibu takut soalnya, tapi biarpun normal tetap butuh biaya kan, terus sama bidan susianti juga saya di suruh urus BPJS supaya meringakan beban saya pas lahiran nanti mba. (P4).

Kalo dari segi biaya kebutuhan kami juga banyak lagian suamiku haya kerja serabutan makanya saya juga ikut membantu suami cari uang makanya saya sibuk julan gorengan jadinya ngak pergi periksa soalnya nanti pas lahiran juga butuh biaya mbak. (P5)

Akibat kurangnya dukungan ekonomi membuat ibu juga harus tetap bekerja membantu suami dalam mencari nafka, walaupun dalam kondisi mengandung sehingga sampai tidak ada waktu untuk melakukan pemeriksaan kehamilan. bahkan ibu dan suami lebih perhatian pada kesiapan ekonomi pada saat kelahiran.

Kendala ekonomi dalam keluarga dapat mempengaruhi kesehatan Ibu hamil hal ini disebabkan tingginya kebutuhan keluarga dari segi ekonomi karena kebutuhan Ibu dan janin selama masa kehamilan. Kebutuhan ekonomi yang cukup besar inilah yang memyebabkan Ibu hamil yang kurang mampu secara ekonomi mengambil keputusan untuk tidak melakukan pemeriksaan antenatal care secara rutin, karena lebih mempersiapkan tabugan demi biaya persalinan dan kebutuhan bayi setelah lahir nanti.

Penelitian ini sependapat dengan penelitian yang dilakukan oleh (Agus \& Horiuchi., 2012) hasil penelitian bahwa ibu hamil yang mendapatkan dukungan penuh secara ekonomi memilih untuk melakukan pemeriksaan kehamilan secara teratur ke tenaga kesehatan, berbeda dengan ibu yang berpenghasilan rendah lebih memilih pengobatan tradisional. Hasil yang sama juga pada penelitian (Lumempouw V.J.R Kundre R.M dan Bataha., 2016) mengatakan bahwa ekonomi keluarga sangat mempengaruhi kunjungan antenatal care.

\section{KESIMPULAN}

Dari hasil penelitian ini dapat disimpulkan bahwa :

a. Kurangnya pengetahuan ibu kan pentingnya pemeriksanan kehamilan secara rutin sehingga menyebabkan ibu tidak melakukan pemeriksaan kehamilan sampai pada pemeriksaan K4.

b. faktor ekonomi yang tidak mendukung menjadi penghambat bagi ibu untuk melakukan pemeriksaan kehamilan, hal ini membuat ibu yang sedang mengandung juga harus berusaha untuk bekerja demi memenuhi biaya persalinan.

c. Kurangnya dukungan motivasi dari keluarga yang membuat ibu hamil tidak melakukan pemeriksaan kehamilan secara lengkap.

\section{SARAN}

1. Perlu adanya peningkatan sosialisi dari dinas kesehatan atau puskesmas mengenai pentingnya antenatal care bagi Ibu dan Janin.

2. Kepada setiap keluarga diharapkan lebih mendukung dan memotivasi ibu hamil agar ibu lebih aktif berkunjung ke pelayanan kesehatan untuk memeriksakan kehamilan.

3. Kepada tenaga kesehatan bidan Puskesmas diharapkan lebih giat lagi melengkapi data keaktifan ibu hamil dalam kunjungan antenatal care, sehinga dapat mengetahu presentasi kunjungan K1 sampai K4 di wilayah kerja.

\section{REFERENSI}

Agus, Y., \& Horiuchi., S. and. (2012).

Factors influencing the use of antenatal care in rural West Sumatra, Indonesia. BMC Pregnancy and Childbirth, 12(9), 1-8.

Anshor dan Ghalib Abudllah. (2010). Parenting With Love. PT. Mizan Pustaka: Bandung, 2(1), 2-6. 
Dian Indriyani. (2013). Aplikasi Konsep Teori Keperawatan. Nuha Media : Yogyakarta, 1-8.

Dinas Kesehatan Provinsi Jawa Tengah. (2018). Profil Kesehatan Indonesia, Profinsi Jawa Tengah Tahun 2018. 1227(July), 1-112.

Febyanti N.K dan Susilawati. (2012). Hubungan Pengetahuan Ibu Hamil Tentang Antenatal Care Terhadap Perilaku Kunjungan Kehamilan. Jurnal Keperawatan Soedirman, $\operatorname{VII}(7), 156-164$.

Friedman. (2013). Keperawatan Keluarga. Gosyeng Publishing : Yogyakarta, 5 6.

Kemenkes. (2016). Pedoman Pelayanan Antenatal Care (Vol. 1227, Issue July).

Lumempouw V.J.R Kundre R.M dan Bataha. (2016). Hubungan Faktor Sosial Ekonomi Ibu Hamil Dengan Keteraturan Pemeriksaan Antenatal Care (ANC) Di Puskesmas Ranotana Weru Kecamatan Wanea Kota Manado. E-Journal Keperawatan, 4(2).

Notoadmojo. (2010). Promosi Kesehatan Dan Ilmu Perilaku. Rineka Cipta : Jakarta, 1(8).

Nur Y M. Setanelly Dan Lestari, L. (2019). Faktor Yang Berhubungan Dengan Pemeriksaan Antenatal Care (ANC). Jurnal Kesehatan, 3, 76-83.

Ritonggo. (2012). Faktor-Faktor Yang Mempengaruhi Kunjungan Pemeriksaan Pada Ibu Hamil. Journal Kesehatan, 12-54.

Siti Mahmudah. (2010). Psikologi Ssoial. UIN Maliki Pres : Malang, 2(1), 110. 01772-1

Sugiyono. (2016). Metode Penelitian Kuantitatif, Kualitatif Dan R\&D. PT Alfabet: Bandung, 185-197.

Susanto, J., Ode, L., Ahmad, A. I., \&
Suriani, C. (n.d.). Faktor Yang Berhubungan Dengan Pemeriksaan Antenatal Care (Anc) Kunjungan 1Kunjungan 4 (K1-K4) Pada Ibu Hamil Di Rsud Kota Kendari Tahun 2016.

Windiyati, \& Pebrian, D. (2017). Faktor Yang Mempengaruhi Kunjungan Antenatal Care Pada Ibu Hamil Di Puskesmas Kampung Dalam. Journal Kebidanan, 4(1), 12-98. 